\title{
Promoting books and places: A study of adjectival modification in persuasion and description
}

\begin{abstract}
This is a study of adjectival modification, that is the use of adjectives and adjectival participles, in the genres of book information and place description. Book information represents a genre with a subtle, covertly persuasive function, while place description is taken to have little or no persuasive force. The study starts out with a quantitative element, establishing lexical densities of the eight texts in the data. This is followed by qualitative analyses of the functions which adjectives have in the genres examined. Answers are sought to these primary questions: 1) What is the role of modifying adjectives in the lexical density of the texts analysed? 2) What discourse functions do these adjectives fulfil in the two genres? The conclusions of the study include: 1) High occurrence of modifying items does not automatically equal nominal style. 2) High occurrence of modifying items is not an automatic sign of high lexical density. 3) The frequent use of modifiers in non-fiction is not limited to persuasion, since adjectives are also frequent in the genre in which the descriptive function is foregrounded.
\end{abstract}

\section{Introduction}

The purpose of this article is to explore how modifying is effected in the genres of book information and place description. Modifiers are here understood as items which realise meanings associated with the classification and description of the participants. The items we are concerned with relate to nouns attributively or predicatively, that is adjectives and adjectival participles (Jackson 1990: 128). We are thus dealing with qualifying elements in discourse. ${ }^{1}$ These in turn are primarily associated with

1 Gordon Tucker (1998: 119), for example, in his systemic-functional approach to adjectives uses 'quality' as the entry condition in the initial system for Quality.

* Hilkka Yli-Jokipii

University of Turku

Department of English Translation Studies

Tykistökatu 4

FIN-20520Turku

hilkka.yli-jokipii@utu.fi 
description and persuasion. Description may either point to fiction and to the aesthetic function of the text, to use Karl Bühler's (1934) canonic classification, or description may be found in non-fiction, contributing towards persuasion. A persuasive strategy may be quite explicit or disguised in a seemingly neutral informative role.

As regards their textual surroundings, modifiers such as adjectives and adjectival participles tend to occur as constituents in noun phrases (see Bhatia 1993: 28; Francis/Kuçera 1982: 10-11). It is therefore tempting to assume that the frequency of such modifiers goes hand in hand with the density or scarcity of noun phrases in the texts concerned. The prevalence of noun phrases in turn is among the primary criteria employed in drawing the stylistic profile of the text and may thus be useful in determining for example the special language quality of the text or assessing its readability.

The study will be carried out using a bottom-up method, which entails a genre analysis of multiple texts (Bhatia 1993: 24-34). The work will start out with a frequency count of the modifying items of adjectives, including adjectival participles. On the basis of this count two texts will then be selected for qualitative analyses of the functions which the modifiers carry out in the discourse concerned. The result of these analyses will be discussed in view of the existing knowledge of the textual and rhetorical characteristics of the types of modifiers investigated. ${ }^{2}$

The texts analysed here represent non-fictional present-day English. The primary focus will be on the genre of book information and the observations based on this genre will be juxtaposed with a sample text representing a non-fictional, but relatively literary text. This will be referred to as the genre of place description. These will be introduced in more detail below.

\subsection{Book information}

The label book information is used here as a countable phrase, referring to a text put out by the issuer of the book usually somewhat prior to the date that the book actually comes out. On the surface, the text indeed seems to inform the readership of what the book is about, yet the

2 A working paper on this study is available in Yli-Jokipii (2001). 
underlying aim of such texts is promotional, to make the readers want to purchase the book. There is thus a difference as to how the reading - or buying - public are informed about the book.

The basic function of book information is persuasive, as its ultimate purpose is to ensure a large demand for the title in question. In this respect, book information is related to blurbs, which are used for marketing the books quite explicitly (see Hiltunen 1996 about blurbs in linguistics books). In book information, however, the text should not display overtly aggressive marketing tactics, because the readers may want to remain confident that they are choosing a book on the basis of criteria other than luring sales text. Therefore, book information tends to be disguised as innocent description of the book concerned, so that the informative element is foregrounded and the persuasive downgraded.

Book information is distributed in a variety of ways. These include leaflets of individual titles, collections of information printed out in a catalogue of books, i.e. a brochure, as well as collections of book information available on the World Wide Web, primarily on the Internet.

\subsection{Place description}

The second genre included in this study is labelled place description. This is a relatively uncommon genre in the sense that although the text introduces actual places, in this case American cities, its explicit purpose is not necessarily to lure readers to visit these places. Instead, the text subtly describes the places in question, drawing on sophisticated essayistic strategies and avoiding the plain style of tourist brochures. Example 1 shows a passage from the beginning of Text 8 , which was used as a sample of such description in the data.

\footnotetext{
Example 1

The City of Angels

Images of sun-bronzed people basking under eternally blue skies, of luxurious swimming pools shaded by tall swaying palm trees, of RollsRoyces and Cadillacs drawn up before palatial mansions that overlook the deep blue Pacific Ocean - all those dreams of success and the ultimate good life this side of paradise have for decades attracted people to southern California's magnetic city of Los Angeles. [...] A city that some believe to be paradise, others regard as the last word in horror; a city that some claim to be exciting, dynamic and romantic, others see as superficial, brash, and selfish...(Inglewood 1984: 144).
} 


\section{Study design}

\subsection{Genre analysis of multiple texts}

The method used in this paper is related to what Bhatia (1993: 24-34) calls for in connection with applied genre analysis. Such research contains a statistical analysis of the surface features of texts and also seeks information about the way communicative purposes are accomplished in a particular genre. Discovering the rationale underlying the selection and distribution of surface features and highlighting the tactical aspect of linguistic variation are indeed among the aims of applied genre analysis. This is taking linguistic description in the direction of explanation.

The present study therefore starts with a quantitative approach whereby the frequencies of adjectives are counted in the individual texts representing the two genres. The results are then compared with the lexical densities of the texts. The term 'lexical density' refers to the proportion of content words, i.e. nouns, verbs and adjectives in proportion to the total number of words in the text (see Georgakopoulou/Goutsos 1997: 110-111; Gustafsson 1990). The higher the proportion of content words in a given text, the greater is the lexical density of this text. High lexical density, in turn, easily reduces the readability of the text.

Moving toward explanation, a qualitative approach is thereafter adopted to explore the functions which adjectives have in these particular genres. The texts with the highest and lowest frequency of adjectives are analysed as examples.

Regarding the concept of genre, this study launches on the default assumption that the texts comprising the group of book information and the text representing place description are genres of their own. This study does not undertake to argue the rationale for such assumption (for further details, see for example Bhatia 1993; Swales 1990; Trosborg 1997: 618).

\subsection{Research questions}

These primary questions were assigned for the study:

1. To what extent are adjectival modifiers characteristic of book information? 
2. What is the role of modifying adjectives in the lexical density of the texts analysed?

3. What discourse functions do these adjectives fulfil in the genre of book information and place description?

\subsection{Data}

The data consist of a judgement sample of eight texts divided into two groups of seven and one, respectively (Texts 1 to 7 and Text 8 ). The criterion in selecting the texts was that the books that they represented had to deal with places, that is geographical locations. The seven-text group is made up of book information texts. Of these, five are from the Book-of-the-Month Club and two from the Sheridan House publishing company. These sources will be explained briefly here before introducing the remaining eighth text.

The Book-of-the-Month Club (henceforth BOMC) is a US-based book club. Unlike a number of other book clubs that have sprung up and eventually disappeared, BOMC has been operating since 1926, and still seems to enjoy a certain distinction in the market. According to the information available on its web site, BOMC sends out a mail-order catalogue to its members regularly and to potential members occasionally. The web site gives information on titles available to non-members as well. The BOMC data used in this study are obtained from its $2001 \mathrm{web}$ site, with the exception of Text 1 , which comes from a printed catalogue sent to me for promotion purposes. The other source of data is Sheridan House publishers. This publishing house primarily features nautical literature.

Text 8 is a comparison sample of a genre which is here labelled as place description. It is an extract from a descriptive essay on Los Angeles, California, entitled "The City of Angels" in Eric Inglewood's (1984) book Cities of America. This 256-page book is a collection of fifty pieces of writings by the same author, each focusing on a different American city. The texts are complemented with photographs and other occasional illustrations. 


\section{Quantitative approach}

\subsection{Word count}

A basic count of the number of words in the texts analysed is available in Table 1. The term 'word' refers to an unlemmatized occurrence of a lexical item, which means that the count is based on typographical features (Gustafsson 1996: 41).

\begin{tabular}{lll} 
Text & \multicolumn{2}{l}{ Word count } \\
\hline 1 & 214 & 214 \\
2 & 261 & 261 \\
3 & 262 & 262 \\
4 & 204 & 204 \\
5 & 236 & 236 \\
6 & 189 & 189 \\
7 & 297 & 297 \\
8 & & 223 \\
\hline Total & $\mathbf{1 6 6 3}$ & $\mathbf{1 8 8 6}$ \\
Mean & $\mathbf{2 3 8}$ & $\mathbf{2 3 6}$ \\
Standard deviation & $\mathbf{3 8}$ & $\mathbf{3 6}$ \\
Median & $\mathbf{2 3 6}$ & $\mathbf{2 3 0}$
\end{tabular}

Table 1. Word count in the data. The texts that the numbers refer to are listed in the References under Sources of Data.

The mean number of words in the seven first texts is 238 , the standard deviation 38 , and the median 236 . The texts are thus quite homogeneous in terms of number of words, which makes them highly comparable (Gustafsson 1990: 59). These counts were used as the basis for determining the length of the passage used in Text 8 . The total number of words in this text was assigned at 223 since the cut was made at a sentence break.

\subsection{Count of adjectives}

The analysis of word classes in Table 2 shows that Text 1 by far contains the highest number of adjectives both in absolute numbers and relative values. The number of adjectives in this text is 38 , which represents 18 percent of the total number of words in the text. 


\begin{tabular}{lcccc} 
& \multicolumn{2}{c}{ Adjectives } & \multicolumn{2}{c}{ Content words } \\
Text & Count & \% of word count & Count & \% of word count \\
\hline 1 & 38 & 18 & 120 & 56 \\
2 & 17 & 7 & 137 & 53 \\
3 & 26 & 10 & 126 & 48 \\
4 & 31 & 15 & 111 & 54 \\
5 & 29 & 12 & 122 & 52 \\
6 & 16 & 9 & 92 & 49 \\
7 & 22 & 7 & 135 & 46 \\
\hline Mean & $\mathbf{2 6}$ & $\mathbf{1 2}$ & $\mathbf{1 2 0}$ & $\mathbf{5 1}$ \\
Standard & $\mathbf{8}$ & $\mathbf{4}$ & $\mathbf{1 5}$ & $\mathbf{4}$ \\
deviation & & & & $\mathbf{5 2}$ \\
Median & $\mathbf{2 6}$ & $\mathbf{1 0}$ & $\mathbf{1 2 2}$ &
\end{tabular}

Table 2. Count and percentages of adjectives and content words in Texts 1 to 7 .

The text at the other end of the scale is Text 2 with 17 adjectives, which account for only a rounded up 7 percent (from 6.5 percent ) of the total count of words in the text. Close to that percentage value for adjectives is Text 7. The percentage of adjectives in that text is 7.4, which likewise amounts to a rounded down figure of 7 percent.

It is interesting to note that the lowest frequency of adjectives in the genre of book information examined here is practically equal to the mean percentage of adjectives (7.7 percent) in Francis/Kuçera's (1982: 547) count of adjectives in Informative Prose in the Standard Corpus of PresentDay American English - the Brown Corpus. This comparison is quite valid because the criteria for analysis listed by Francis/Kuçera (1982: 11) were also used in the present study.

\subsection{Adjectives and lexical density}

The lexical density of the texts was analysed in order to determine the role of adjectives in the context of the stylistic quality of the texts. With 46 percent, Text 7 has the lowest frequency of content words, as Table 2 above shows. Text 1 has by far the highest density, 56 percent, but close to this is also Text 4 with 54 percent. The high density of content words in the texts that have low percentages of adjectives (Texts 2 and 6 in particular) tells us that the lexical density of a text can be high without a 
72

high concentration of adjectives, and therefore adjectives do not seem to be an undisputed constituent in a high lexical density.

Lexical density may thus be achieved with a high frequency of nouns and verbs only. Texts 3 and 6 are examples of texts with a low percentage of adjectives (10 and 9 percent, respectively), but with a relatively high rate of content words ( 48 and 49 percent, respectively). An extract from Text 6 is shown below:

Example 2

In Tuscany is a window on the world of feasts and festivals, food and wine, people and culture. Through Mayes's lyrical prose and Bob Krists's spectacular photographs, the book takes you from the piazzas and medieval courtyards to the hunt for mushrooms, the harvest of the grape, and the first olive pressing.

$[\ldots]$

From the indescribable Tuscan light on a sublime landscape to a pile of marmalade cats asleep in the sun, In Tuscany puts you right there in the center of one of earth's most beautiful places (original emphasis).

The above passage illustrates that the lexical density of a text may be quite high in spite of its few adjectives. As high lexical density is associated with nominal style, we may argue that adjectives are not indispensable components of such style.

\subsection{Comparison of genres}

The foregoing frequencies were all from the book information. These figures will now be compared with the frequency of adjectives in the less persuasive genre of place description exemplified by Text 8 .

\begin{tabular}{lllll} 
& \multicolumn{2}{l}{ Adjectives } & \multicolumn{2}{l}{ Content words } \\
\hline Text & Count & \% of word count & Count & \% of word count \\
\hline 1-7 Mean & 26 & 12 & 120 & 51 \\
8 & 30 & 13 & 113 & 51 \\
\hline
\end{tabular}

Table 3. Count and percentages of adjectives and content words in Texts 1 to 7 (mean values) and Text 8 .

The comparison is enunciated in Table 3, in which the number and percentage of adjectives, and the number and percentage of content words 
in Text 8 are viewed against the corresponding mean values for Texts 1 to 7. The comparison shows that percentagewise the two genres are nearly identical with respect to the frequency of adjectives and totally identical in terms of lexical density.

\section{Qualitative approach}

\subsection{Function analysis of modifiers in texts}

In order to be able to arrive at a comprehensive account of the roles of the adjectival modifiers in the text, their function in discourse was analysed to see what goals were instrumented through them. This yielded the following classification:

a) Contribute to contents

b) Create atmosphere

c) Evaluate

d) Other functions.

Let us now take a closer look at two texts in order to see how modifiers are put to use along this classification. We will first look at Text 1 , in which adjectives make up 18 per cent of the text, meaning that nearly every fifth word has a modifying function.

\subsubsection{Analysis of Text 1}

Text 1 in the data is a description of a BOMC book entitled Cuba: 400 Years of Architectural Heritage. According to the description, the book contains photographs of Cuban architecture supplemented with commentary looking back into 400 years of Cuban history. We may thus assume that the description is largely aimed at readers interested in history and the arts, and architecture in particular. Readers contemplating a visit to Cuba are included in the potential readership as well. The rhetorical strategy of the text is therefore to appeal to specialists, such as experts in the arts, history and architecture each per se, or a mixture of these.

a) Contribute to contents

Adjectives that contribute to the contents of a text are items that add to its information load, but remain neutral in terms of local or cultural as- 
74

pects. Example 3 will illustrate this. The adjectives in question are printed in italics.

Example 3

Because there has been little recent development, this beautiful island doesn't suffer from the kind of modern blight so prevalent elsewhere.

Entire towns seem frozen in time...

In this view, the temporal adjectives recent and modern are seen as contentgiving items, while they are also, naturally, elements that simultaneously support the temporal macrostructural strand of the text.

b) Create atmosphere

The adjectives that create atmosphere in this text primarily refer to historical or geographical items. Example 4 shows adjectives that describe the historical aspect of the book. In this example they highlight the Spanish and Moorish atmosphere in Cuba:

Example 4

The long period of Spanish colonialization is evident everywhere: in the logical, well-designed, and defended cities, the patios of colonial houses, the Moorish touches in decorative tiles...

Geographical adjectives include of course Cuban and Caribbean, but also (North) American and Spanish. The following extract from the text is an example of this:

Example 5

As visitors know, the country exhibits a peculiarly Cuban sense of color and ornament, a blend of the European and the Caribbean. [...]

The long period of Spanish colonialization is evident everywhere...

This example also shows an interesting extension of the use of the words European and Caribbean. In strict grammatical terms, these are used as nouns here, but their isolated form resembles an adjective. These words are, however, not counted as modifiers in this paper.

c) Evaluate

Evaluation with the means of adjectives is twofold. The evaluation either concerns the topic of the book, or the book itself. Example 6 will show how adjectives are put to use to evaluate the topic of the book described: 
Example 6

Cuba is in a unique position, and not just geographically. Because there

has been little recent development, this beautiful island...

Example 7 illustrates an interesting use of the adjective precious: It seems to be evaluating the topic of the book, but its vicinity to the title of the book is bound to cast its effect on the book itself as well.

Example 7

Cuba: 400 Years of Architectural Heritage celebrates this precious architectural history (original emphasis).

However, the evaluative adjectives indisputably focusing on the book itself are more frequent, such as ... this lovely volume ... with illuminating commentary and breathtaking photography ... this splendid architectural history ... a remarkable legacy...

d) Other functions

The category of Other functions comprises the adjectives that do not easily fall into any of the above categories. Example 8 contains most of these, such as Royal and the French adjectives Beaux and Nouveau:

Example 8

You'll discover North American Beaux Arts design in the Royal Bank of Canada in Santiago and in other buildings by Mc Kim, Mead \& White. Art Deco flourishes and so does Art Nouveau.

\subsubsection{Analysis of Text 2}

As shown in Table 2 above, Text 2 has the lowest frequency of adjectives and thus represents the other extreme in the frequency counts. Curiously enough, Cuba is also the topic of this text, as it describes a book entitled Sailing to Hemingway's Cuba, written by Dave Schaefer. Example 9 below gives an indication of the character of the book.

a) Contribute to contents

The first paragraph of this four-paragraph text contains only three adjectives, and even two of those are borderline cases. All the adjectives in the first paragraph qualify the contents of the text.

Example 9

Dave Schaefer, who lives in Burlington, Vermont, decided that his "some day I'll go cruising" dream would start now. The destination would be 
forbidden Cuba, the home of his high school hero, Ernest Hemingway. Often alone and sometimes with a crew made up of friends who joined him when they could, Schaefer and his 20-year-old, 32-foot sloop DREAM WEAVER made a 2000 mile (sic) voyage to the Florida Keys. The plan: First, poke around in Hemingways's quirky Key West. Then, haul anchor, sail west above the Gulf Stream, turn south in the darkness and watch the skyline of Havana rise out of the morning mist.

b) Create atmosphere

However, as in Text 1, the adjectives are there primarily to create the Cuban atmosphere. There are the local and cultural adjectives, such as Cuban and American, and also the character-giving Spanish, Colonial etc, as shown in Example 10:

Example 10

While the government denounces America and Americans, Cubans welcome American sailors and dollars, love Hemingway, and wink at the laws. Old Havana, once the Queen of the Caribbean, is a stunning Spanish Colonial city of hot music, beautiful women, spies, exceptional rum, the worlds's best cigars, and a Cuban spirit that refuses to be repressed.

c) Evaluate

Example 10 above also contains evaluative adjectives, such as stunning, beautiful, exceptional, best. These appraise the topic of the book described, i.e. Cuba, while no evaluative adjectives are employed in this text to promote the book. The contrast with which Cuba is characterized in this text as compared to Text 1 is remarkable.

d) Other functions

We may use Example 9 above to note the type of borderline cases that a text may contain. For example, it is difficult to assign the adjective high any specific functional role in the phrase high school hero.

\section{Conclusions}

I employed a quantitative frequency analysis together with a qualitative discourse analytical methodology in this paper. First I quantified the lexical data in order to find out to what extent modifying items, that is adjectives and adjectival participles, were used in the genre of book information and compared the findings with those of a representative text 
from the genre of place description. I then took the text with the highest value and performed a qualitative analysis to explore the functions that adjectives seemed to have. This approach yielded a four-class classification of the discourse functions of adjectives in the genre of book information: a) contribute to contents; b) create atmosphere; c) evaluate; d) other functions. I then employed this classification on the text that represented the other extreme in the quantitative analysis (Text 2) to see if this classification applied to this text as well - which it did.

We may thus safely assume that the classification produced by the qualitative analysis performed in this study is suited for an analysis of the use of modifiers in the genre of book information. An interesting point to be raised here is that this method should also serve quantitative methods relatively well. Yet, when dealing with the quantification of discoursal elements, we may occasionally encounter such subtleties of discourse that do not fall into neat categories. The overlaps pointed out in the present sample analyses are good examples of such cases.

What conclusions can be made on the basis of the results obtained by using such approaches as employed here? First, the study shows that generalizations regarding the genre qualities on the basis of an analysis of only one exemplar of that genre can be totally wrong. For example, had Text 1 in the present data been used as a sole example of the use of adjectives in the genre of book information, the analysis would have warranted me to claim that such abundant use of this word class is characteristic of this genre. I would even have been tempted to explain that adjectives are used to contribute to the persuasive function of book information. The quantitative evidence however showed that such claims are clearly ungrounded. Second, the present paper also shows that a quantitative approach supplemented with a text-external, pragmatic viewpoint gives a comprehensive account of the subtleties of language use.

Modification is used in non-fictional genres in a versatile manner. In place descriptions, modifiers are indeed used primarily as descriptive instruments. In this genre, their function is to increase the content and to create - or help create - the atmosphere that the text communicates. Even when modifiers are assigned an evaluative role, the evaluation naturally concerns the topic of the text alone. In the genre of book information, modifiers of course have descriptive roles as well, but in 
addition to these, they are assigned multiple evaluative roles. The assessment may namely have various foci, such as 1) the topic covered by the book, 2) the book itself, or 3) the author of the book - the author however only occasionally. Furthermore, in the present genre of place description, the descriptive use of modifiers contributes to the aesthetic effect of the text while in book information certain groups of the descriptive modifiers serve a hidden persuasive agendum.

The modifiers analysed in this study do not seem to carry the straightforward textual characteristics that one might easily have attributed to them on the basis of established knowledge. For example, an assumption at the outset might be that a high occurrence of adjectives and adjectival participles would coincide with a high lexical density which the frequent use of noun phrases tends to produce. While this is true for some texts in the data, the relationship is not a consistent one, as some texts had a high lexical density but yet contained relatively few modifying items. As indicated above, another false assumption might have been that a high occurrence of adjectives would be characteristic of persuasion and of the genre of book information. However, the large proportion of such items also found in place descriptions indicates that adjectival modifiers alone cannot validly be labelled as characteristic to persuasion alone. This is not to say that, for example, the evaluative use to which certain modifiers are put in the present data does not serve persuasive strategies, but such use concerns only a limited proportion of adjectives in the text.

Finally, let us summarize the conclusions of this study:

1) Modifiers appear in descriptive and evaluative roles in the genres studied. In both roles, the explicitness of their use varies.

2) The frequent use of modifiers in non-fiction is not limited to a persuasive genre alone, as these can also be frequent in a non-persuasive genre.

3) High occurrence of modifying items, such as adjectives and adjectival participles, cannot be claimed to automatically belong to a nominal style.

4) High occurrence of modifying items, such as adjectives adjectival participles, cannot be claimed to automatically belong to a text with high lexical density. 


\section{Implications for further research}

The findings in the present study raise a number of questions that warrant further investigation. For example, it would be interesting to follow up on the textual qualities of texts dense in modifiers: Under which conditions - and in which genres - does a high frequency of the modifying items analysed here coincide with a highly nominal style? Similarly, it would be worth investigating under which conditions and in which genres a high frequency of modifiers coincides with a high lexical density. It would further be interesting to involve writer and reader issues and consider how conscious discourse strategies are effected through modification, and conversely how readers respond to such strategies.

\section{Sources of data}

The numbers match the numbering used in the text.

1. Cuba: 400 Years of Architectural Heritage. BOMC catalogue.

2. Sailing to Hemingway's Cuba. www.sheridanhouse.com.

3. In a Sunburned country. www.bomc.com

4. Spain. A History. www.bomc.com

5. 1700. Scenes from London Life. www.bomc.com

6. In Tuscany. www.bomc.com

7. Sell up and Sail. Taking the Ulysses Option. www.sheridanhouse.com

8. Inglewood, Eric 1984: Cities of America. London etc.: Hamlyn. 114-122.

\section{References}

Bhatia, Vijay 1993: Analysing Genre: Language Use in Professional Settings. London: Longman.

Bühler, Karl 1934: Sprachtheorie: Die Darstellungsfunktion der Sprache. Jena: G. Fischer.

Francis, W. Nelson/Kuçera, Henry 1982: Frequency Analysis of English Usage: Lexicon and Grammar. Boston: Houghton Mifflin Company.

Georgakopoulou, Alexandra \& Goutsos, Dionysis 1997: Discourse Analysis. An Introduction. Edinburgh: Edinburgh U.P.

Gustafsson, Marita 1990: Lexical density as a style marker. In Battarbee, Keith/Hiltunen, Risto (eds). Alarums and Excursions. Working Papers in English. (Publications of the Department of English 9). University of Turku 45-60.

Gustafsson, Marita 1996: Sailor or Lawyer? Interpreting a Maritime Document. In Gustafsson, Marita (ed.). Essayes and Explorations. A 'Freundschrift'for Liisa Dahl. (Anglicana Turkuensia 15). Turku: University of Turku, 37-48. 
Hiltunen, Risto 1996: Getting scholarship across: some discourse strategies in academic marketing. In Gustafsson, Marita (ed.), Essayes and Explorations. A 'Freundschrift' for Liisa Dahl. (Anglicana Turkuensia 15). Turku: University of Turku, 49-61.

Jackson, Howard 1990: Grammar of Meaning. A Semantic Approach to English Grammar. London/New York: Longman.

Swales, John 1990: Genre Analysis: English in Academic and Research Settings. Cambridge: Cambridge U.P.

Trosborg, Anna 1997: Text Typology: Register, Genre and Text Type. In Trosborg, Anna (ed.). Text Typology and Translation. Amsterdam/Philadelphia: Benjamins, 3-23.

Tucker, Gordon 1998: The Lexicogrammar of Adjectives: A Systemic-Functional Approach to Lexis. London: Cassell.

Yli-Jokipii, Hilkka 2001: Lexis in Non-Fictional Genres: An Exploration into Adjectives as Discourse Instruments. In Hiltunen, Risto/Battarbee, Keith/Peikola, Matti/ Tanskanen, Sanna-Kaisa (eds). English in Zigs and Zags. (Anglicana Turkuensia 23). Turku: University of Turku, 315-330.

\section{Appendix}

Text Samples

\section{Text 1}

Cuba: 400 Years of Architectural History

Cuba is in a unique position and not just geographically. Because there has been little recent development, this beautiful island doesn't suffer from the kind of modern blight so prevalent elsewhere. Entire towns seem frozen in time, some of them virtually untouched in four centuries. Cuba: 400 Years of Architectural Heritage celebrates this precious architectural history.

As visitors know, the country exhibits a peculiarly Cuban sense of color and ornament, a blend of the European and the Caribbean. This lovely volume is the first to capture the special quality found in all quarters of the diverse tropical land.

With illuminating commentary and breathtaking photography, the book explains the structures themselves and the wealth of influences that shaped them. The long period of Spanish colonialization is evident everywhere: in the logical, well-designed, and defended cities, the patios of colonial houses, the Moorish touches in decorative tiles, and the expressions of Spanish baroque in the Havana Cathedral. You'll discover North Ameri- 
can Beaux Arts design in the Royal Bank of Canada in Santiago and in other buildings by McKim, Mead \& White. Art Deco flourishes and so does Art Nouveau.

From early Coastal forts to post-revolutionary apartment buildings, this splendid architectural history preserves a remarkable legacy that is increasingly at risk.

\section{Text 8}

Images of sun-bronzed people basking under eternally blue skies, of luxurious swimming pools shaded by tall swaying palm trees, of Rolls Royces and Cadillacs drawn up before palatial mansions that overlook the deep blue Pacific Ocean - all those dreams of success and the ultimate good life this side of paradise have for decades attracted people to southern California's magnetic city of Los Angeles. More than any other city in the United States, except perhaps New York, Los Angeles arouses strong emotional responses, and its character depends more on the eye and the mood of the beholder than on any absolute truths. A city that some believe to be paradise, others regard as the last word in horror; a city that some claim to be exciting, dynamic and romantic, others see as superficial, brash and selfish. Long the center of the world's greatest movie-making industry, the city's Hollywood district has itself been the creator of such dreams, in which the great movie stars represented the epitome of success and glamour to ordinary folk engrossed in the more mundane and harsher realities of everyday life. Contrasts between myth and reality, success and failure, beauty and ugliness color the many-sided nature of this fascinating city and help to explain local attitudes and behavior, for here the worst disaster of all is to be old, poor or ugly. 
